\title{
ANÁLISE DA ASSOCIAÇÃO ENTRE CARACTERÍSTICAS TOPOGRÁFICAS E TIPOS DE OCORRÊNCIA DE PROCESSOS EROSIVOS AO LONGO DE LINHA FÉRREA - ESTUDO DE CASO: MALHA PAULISTA - ALL (SP)
}

Analysis of association between topographical features and types of erosion's occurrence events along of railway line - case study: Paulista Rail Network - ALL $(S P)$

\author{
NATÁLIA DA COSTA SOUZA ${ }^{1}$ \\ MARIANA ABRANTES GIANOTTI ${ }^{1}$ \\ ANA PAULA CAMARGO LAROCCA ${ }^{2}$ \\ JOSÉ ALBERTO QUINTANILHA ${ }^{1}$ \\ GERSON SALVIANO DE ALMEIDA FILHO ${ }^{3}$ \\ ${ }^{1}$ Escola Politécnica da Universidade de São Paulo - EPUSP \\ Departamento de Engenharia de Transportes \\ Av. Prof. Luciano Gualberto, Travessa 03, $\mathrm{n}^{\circ} 380$ \\ CEP: 05508-010, São Paulo - SP - Brasil \\ ${ }^{2}$ Escola de Engenharia de São Carlos da Universidade de São Paulo - EESC/USP \\ Departamento de Engenharia de Transportes \\ Av. Trabalhador Sãocarlense, 400 \\ CEP: - 13566-590, São Carlos - SP - Brasil \\ ${ }^{3}$ Instituto de Pesquisas Tecnológicas - IPT \\ CTGEO - Laboratório de Riscos Ambientais - LARA \\ Av. Prof. Almeida Prado, 532 \\ CEP: 05508-901, São Paulo - SP - Brasil \\ nataliacostaptr@usp.br; mariana.giannotti@usp.br; larocca.ana@usp.br; \\ jaquinta@usp.br; gersaf@ipt.br
}

\begin{abstract}
RESUMO
A ocorrência de eventos erosivos acelerados associados à implantação de sistemas de transportes é um dos principais problemas socioambientais enfrentados pelas
\end{abstract}


concessionárias brasileiras. Feições erosivas do tipo linear e laminares são observadas tanto ao longo da plataforma, nos cortes e aterros, como fora dela, em caixas de empréstimo, áreas de jazidas exploradas, junto aos pés de aterros e jusante das obras de transposição. Além da compreensão das interações entre fatores condicionantes dos processos erosivos, é necessário estudar isoladamente cada um dos fatores com bastante detalhe para se compreender como, onde e por que a erosão ocorre. Dentre esses fatores, os atributos topográficos ou características das vertentes estão entre uma série de elementos controladores da distribuição dos processos erosivos. Sua importância para o desenvolvimento desses fenômenos advém do fato da topografia controlar a intensidade e direção dos fluxos hídricos pluviais, que por sua vez são os principais agentes erosivos no meio tropical úmido. Nesse contexto, através do uso de tecnologias geoespaciais e medidas estatísticas de associação nãoparamétrica, este artigo apresenta uma análise da relação entre diferentes tipos de processos erosivos (classificados de acordo com suas características próprias e graus de gravidade) e seus respectivos valores de declividade e hipsometria das vertentes as quais estão localizados. A área de interesse é restrita às análises e registros de processos erosivos diagnosticados no trecho que interliga as cidades de Mairinque (SP) a Botucatu (SP), totalizando um trajeto de aproximadamente $176 \mathrm{~km}$. A comparação dos resultados permitiu avaliar a importância da variável espacial na problemática tratada. A análise dos testes estatísticos não-paramétricos apontou que existe associação estatisticamente significativa entre as variáveis estudadas. Já as técnicas de geoprocessamento e o uso de informações espaciais, apesar de não fornecerem um valor estatístico que permita inferir a associação entre as variáveis analisadas, possibilitaram a observação da distribuição espacial dos fenômenos de erosão ao longo do trecho da ferrovia, indicando que tal comportamento não aponta, claramente, associação expressiva entre os tipos de processos e as características topográficas consideradas.

Palavras-chave: Erosão; Linha Férrea; Sistemas de Informação Geográfica (SIG); Característica Topográfica; Estatística não-paramétrica.

\section{ABSTRACT}

The occurrence of accelerated erosion events associated with the implementation of transport systems is a major environmental problems faced by the Brazilian utilities. Erosive features of linear and laminar type are observed both along the platform, in the section sand embankments, and outside in boxes loan areas explored deposits, at the foot of embankments and downstream of the works of Transposition. In addition to understanding the interactions between conditioning factors of erosion, it is necessary to study separately each factor with enough detail to understand how, where and why erosion occurs. Among these factors, topographic attributes or characteristics of the slopes are among a number of factors controlling the distribution of erosion. In this context, by the use of geospatial tools and technologies and non-parametric statistical measures of association, this article presents an analysis of the relationship between different types of erosion (classified

Bol. Ciênc. Geod., sec. Artigos, Curitiba, v. 20, nº 4, p.947-969, out-dez, 2014. 
according to their own characteristics and degrees of severity) and their respective values of slope and hypsometry the slopes, which are located. The area of interest is restricted to the analysis and records of erosion diagnosed in the stretch that connects the cities of Mairinque (SP) and Botucatu (SP), totaling a path of about $176 \mathrm{~km}$. The comparison of the results allowed to evaluate the importance of the spatial variable in the problem treated. The analysis of non-parametric statistical tests showed that there is a statistically significant association between variables. On the other hand, GIS techniques and the use of spatial information, in spite of not providing a statistical value - that allows to infer the association between the variables analyzed-, allowed the observation of the spatial distribution of the phenomena of erosion along the stretch of the railroad, indicating that such behavior not clearly indicates significant association between the types of processes and topographical characteristics considered.

Keywords: Erosion; Rail Network; Geographic Information Systems (GIS); Topographical Feature.

\section{INTRODUÇÃO}

Os processos erosivos ocorrem quando a resultante de todas as forças atuantes sobre o material erodível excede o resultado efetivo de todas as forças que tendem a conservar o material no próprio local (SIMONS, 1982). Desta forma, pode-se classificar erosões como processos geológicos de desbaste da superfície terrestre. São frutos da interação entre solo, água, clima e características topográficas, em que ocorre a retirada e o transporte do material na forma de fragmentos, soluções e colóides.

De forma geral, as erosões são classificadas em lineares (sulcos, ravinas e voçorocas) e laminares. A erosão laminar (BERTONI \& LOMBARDI NETO, 1990), ou erosão em lençol (GUERRA e CUNHA, 1994 e 1995), ou, ainda, erosão superficial (BIGARELLA; MAZUCHOWSKI, 1985) é o início do processo erosivo. $O$ processo surge do escoamento da água que não se infiltra, por meio do escoamento superficial difuso, após o impacto das gotas da chuva ao atingir o solo. É o procedimento de lavagem da superfície do terreno com transporte das partículas sólidas do solo. Inicia-se com a desagregação destas partículas pela energia das gotas de chuva. Bigarella e Mazuchowski (1985) definem que a erosão em sulcos sucede a laminar, podendo igualmente originar-se de precipitações muito intensas. Para Bertoni e Lombardi Neto (1985), as erosões em sulco são também formadas por concentrações do escoamento que podem formar filetes, mais ou menos profundos, em consequência do volume e velocidade do escoamento superficial. Das feições lineares, os sulcos são pouco profundos (inferior a $50 \mathrm{~cm}$ ), sendo que suas bordas possuem pequenas rupturas na superfície do terreno e, podem ser mais facilmente corrigidos por meio da melhoria do manejo do solo. Já a ravina é um sulco profundo no solo provocado pela ação erosiva da água de escoamento superficial concentrado, e que não pode ser combatido pelos métodos simples de 
conservação do solo. Como ravinamento, entenda-se a erosão causada simplesmente pela concentração do escoamento superficial, processo este que, na maioria das vezes, coroa a degradação do solo iniciada pela erosão laminar. As ravinas são feições de maior porte, profundidade variável, de forma alongada e não atingem o nível d'água subterrânea, onde atuam mecanismos de desprendimento de material dos taludes laterais e transporte de partículas do solo. Por fim, as voçorocas representam a forma de erosão mais complexa e mais destrutiva no quadro evolutivo da erosão linear. A bibliografia é quase unânime em associar o surgimento das voçorocas a alterações no equilíbrio morfo-hidro-pedológico, causadas por intervenções humanas, especialmente por meio do desmatamento, atividades agrícolas e, mesmo, urbanas.

A ocorrência de eventos erosivos acelerados associados à implantação de sistemas de transportes é um dos principais problemas socioambientais enfrentados pelas concessionárias brasileiras. Feições erosivas do tipo linear, principalmente, são observadas tanto ao longo da plataforma, nos cortes e aterros, como fora dela, em caixas de empréstimo, áreas de jazidas exploradas, junto aos pés de aterros e jusante das obras de transposição. A imprecisão dos projetos de drenagem, principalmente por não levarem em conta a natureza dos terrenos quanto à suscetibilidade à erosão, o desinteresse pelos investimentos em obras complementares e a falta de manutenção das vias são as principais causas da grande incidência desses processos (SALOMÃO, 1999). A obstrução das vias causada pela dinâmica de desenvolvimento de processos erosivos e outros eventos associados (como deslizamentos de terra) compromete os responsáveis pela operação não só do ponto de vista econômico (paralização das vias e impedimento do transporte de cargas e passageiros), mas principalmente do ponto de vista socioambiental (acidentes envolvendo passageiros e maquinistas, derramamento de cargas inflamáveis, contaminação do solo e lençóis freáticos, exposição da fauna local, etc).

Especificamente no setor ferroviário, para processos de licenciamento ambiental e regularização dos empreendimentos em operação, o Instituto Brasileiro do Meio Ambiente e dos Recursos Renováveis (IBAMA) prevê a implantação de planos e programas ambientais que alcancem o cumprimento das condicionantes necessárias à regularização e funcionamento adequado das atividades em operação no país.Tais programas visam à minimização de danos provenientes da operação da malha, resultando no gerenciamento eficaz dos riscos de suas atividades, possibilitando a mitigação em caso de eventuais impactos aos meios físicos, bióticos e socioeconômicos. Nesse contexto, um dos aspectos abordados dentre os programas exigidos é a análise das ocorrências de processos erosivos ao longo da faixa de domínio da malha, o diagnóstico da gravidade dos processos, sua espacialização e padrões de distribuição, ações de prevenção e recuperação das áreas afetadas (IBAMA, Resolução CONAMA 349, 2004).

$\mathrm{Na}$ literatura, em geral, são aplicados modelos quantitativos e qualitativos para análise da susceptibilidade dos terrenos à ocorrência de processos erosivos (SPÖRL,

Bol. Ciênc. Geod., sec. Artigos, Curitiba, v. 20, nº 4, p.947-969, out-dez, 2014. 
2007). Esses estudos estão inseridos nas concepções de análise integrada da natureza e nas modelagens desenvolvidas pela cartografia geotécnica e geoambiental. Ambas interpretações são análises sistêmicas que visam à compreensão do ambiente físico e dos processos antrópicos, de forma simultânea.

Além dessas abordagens, alguns autores analisam a atuação isolada de fatores condicionantes do desenvolvimento dos processos erosivos, como é o caso de Almeida Filho (2000), Stábile e Vieira (2009), Vidal-Torrado et al. (2005), Shixian Gu (2011). Como completa Morgan (2005), além da compreensão das interações entre fatores condicionantes dos processos erosivos, é necessário estudar isoladamente cada um dos fatores com bastante detalhe para se compreender como, onde e por que a erosão ocorre. Dentre esses fatores, os atributos topográficos ou características das vertentes (declividade, hipsometria, tipo de vertente, etc) estão entre uma série de elementos controladores da distribuição dos processos erosivos. Sua importância para o desenvolvimento desses fenômenos advém do fato da topografia controlar a intensidade e direção dos fluxos hídricos pluviais, que por sua vez são os principais agentes erosivos no meio tropical úmido (DAEE, 1990; COELHO NETTO, 1994; GUERRA, 1994; LEPSCH, 2000). A compreensão de como os atributos topográficos atuam no desenvolvimento de feições erosivas e sua resultante é de especial interesse aos estudos das engenharias e ciências da terra (ANTONANGELO e FENNER, 2005; PINHEIROe CUNHA, 2011; PANACHUKI, 2010). Tais estudos apresentam como característica coincidente a busca de menores impactos da ação humana na naturezae o alcance do patamar de sustentabilidade econômica e ambiental.

Aliado aos processos de pesquisa dessas áreas, e no que tange à dinâmica de compreensão do desenvolvimento de processos erosivos, tipologias e classificações, formas de mitigação e controle, causas, localização e distribuição espacial, a ciência e os sistemas de informações geográficas têm sido ferramentas amplamente utilizadas (DE ROO, 1998; ZHAO et al, 2002; BARTSCH etal, 2002; BOULKHEIR, 2006; SHUHUA e LIJUN, 2011, MANFRÉ et al, 2011). Em estudos capazes de subsidiarem processos de licenciamento, controle, análise e monitoramento ambiental, vários autores discutem a aplicação de técnicas de geoprocessamento, sensoriamento remoto e sistemas globais de navegação por satélite (GPS), enfatizando a capacidade de manuseio de dados espaciais em SIG's, sua eficácia de análise e rapidez de processamento, contextualizando-os nas questões que contemplam os desafios de conciliar o desenvolvimento econômico à conservação do meio ambiente.

\section{2. ÁREA DE ESTUDO}

A área de estudo pertence à região do traçado da linha ferroviária Malha Paulista, operada pela América Latina Logística - ALL. Alinha, em operação, liga a Baixada Santista/Porto de Santos às cidades de Santa Fé do Sul, Panorâma e Colômbia (SP), totalizando um percurso de $1.989 \mathrm{~km}$, possibilitando o escoamento da produção agropecuária e industrial estados de Mato Grosso, Mato Grosso do Sul 
e São Paulo (ALL, 2013). A região de interesse é restrita às análises e registros de processos erosivos diagnosticados no trecho que interliga as cidades de Mairinque (SP) a Botucatu (SP), totalizando um trajeto de aproximadamente $176 \mathrm{~km}$ (Figura 1). A região considerada representa os municípios que interceptam o trecho da linha férrea analisado.

Figura 1 - Mapa da região de estudo: Malha Paulista (recorte) - ALL.

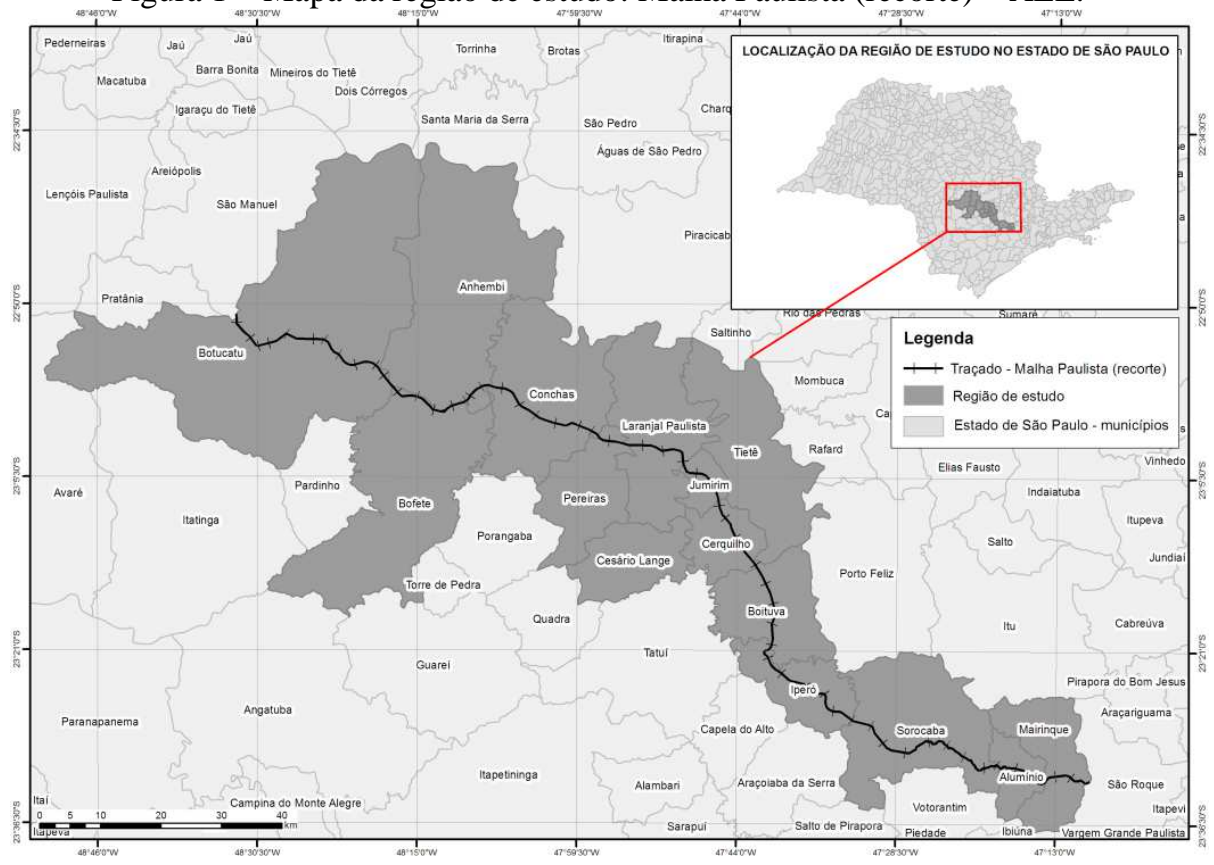

Quanto às características ambientais, observa-se a predominância de ocorrência de argissolos e alissolos, sendo a área de interesse regiões com topografia mais acentuada ao longo da malha ferroviária. Os principais produtos transportados pela Malha Paulista são grãos e minérios. No trecho estudado, a movimentação é restrita ao transporte de cargas e os principais produtos transportados são: minério de ferro, soja, açúcar, manganês, derivados de petróleo e álcool (IPEA, Ministério dos Transportes, 2010). A justificativa para escolha da área de interesse dá-se por conta da incidência de registros verificados no trecho, a importância econômica da linha e a atenção dada pela mídia local aos impactos negativos gerados pela ocorrência de fenômenos erosivos na região (principalmente dos municípios pertencentes à região de Bauru). 


\section{OBJETIVOS}

Através da geração de dados topográficos, classificação e espacialização dos processos erosivos ao longo das vias, pretendeu-se realizar, em plataforma SIG e através de testes de estatística não-paramétrica, uma análise da distribuição de ocorrência dos diferentes tipos de eventos encontrados e suas predominâncias nos intervalos hipsométricos e classes de declividade existentes. Baseado em metodologias já difundidas (CREPANI, 2001; ROSS, 1994, SALOMÃO, 1999; STÁBILE, 2009), e sabendo que a topografia é um parâmetro essencial à definição da dinâmica hídrica de uma vertente e consequentemente ao desencadeamento de processos erosivos, o presente trabalho tem como objetivo analisar a associação entre características topográficas (declividade e hipsometria) e o tipo de processo erosivo que se desenvolve ao longo de parte da linha férrea Malha Paulista- ALL.

\section{MATERIAS E MÉTODO}

A metodologia para desenvolvimento da pesquisa baseou-se em três etapas distintas. A Figura 2 resume o procedimento realizado, os materiais utilizados e os produtos resultantes. $\mathrm{O}$ detalhe de cada etapa será descrito nos subitens a seguir.

Figura 2 - Fluxograma Metodológico, Materiais Utilizados e Produtos.

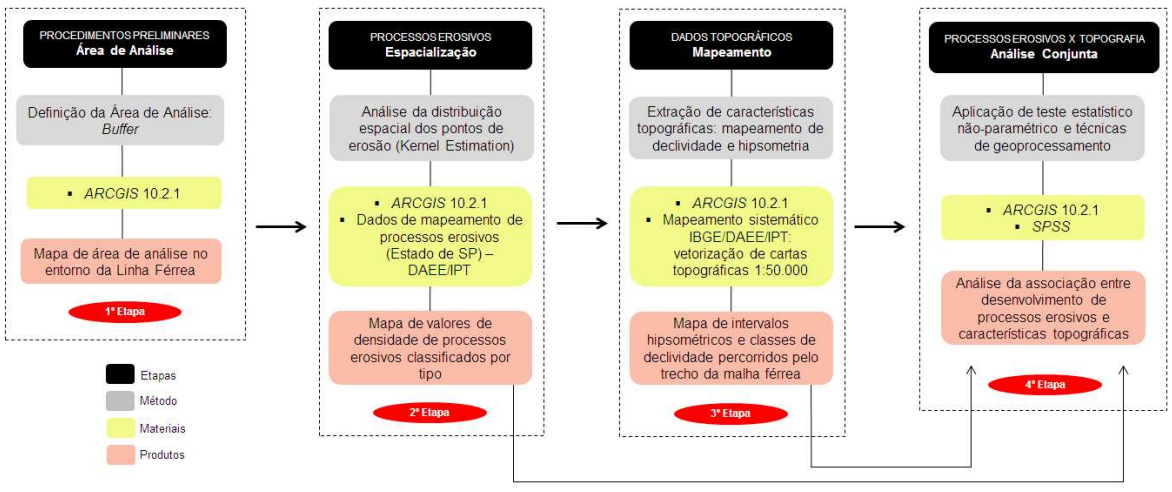

\subsection{Etapa 1: Procedimentos Preliminares: Definição da Área de Análise}

Judicialmente, a faixa situada à margem da ferrovia, chamada faixa de domínio, é uma área de terreno com pequena largura em relação à extensão e varia de acordo com cada trecho em todo o território nacional. Na impossibilidade de se trabalhar com uma faixa comum a todo trecho selecionado, na intenção de facilitar o processo de análise e de considerar principalmente os processos erosivos com desenvolvimento próximos às cabeceiras de drenagem que circundam a linha férrea em questão, optou-se por delimitar a área de análise a um buffer (área de influência) de $3 \mathrm{~km}$ de abrangência. Para tal procedimento, utilizou-se o software ARCGIS 10.2.1 (módulo Analysis Tools - Proximity - Buffer). A delimitação da área de 
análise pode ser vista na Figura 3.

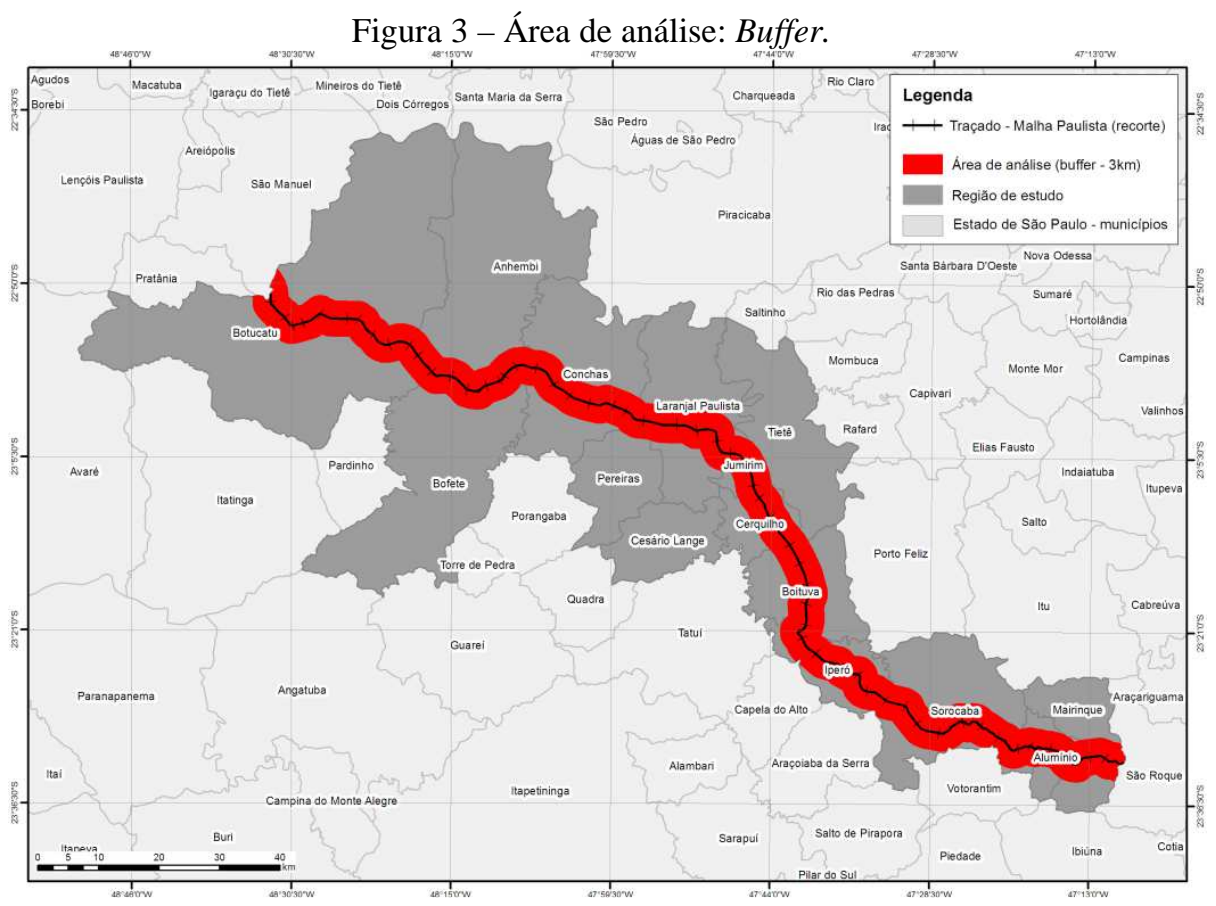

\subsection{Etapa 2: Processos Erosivos - Espacialização}

A base de dados de registro de processos erosivos da área de estudo foi fornecida pelo Instituto de Pesquisas Tecnológicas - IPT e pelo Departamento de Águas e Energia Elétrica do Estado de São Paulo - DAEE, fonte de um projeto cujo objetivo principal é fornecer elementos básicos para o planejamento de programas e ações voltadas ao equacionamento dos problemas causados pelas erosões lineares, urbanas e rurais, e pelas inundações/enchentes nas áreas urbanas de todo o território do Estado de São Paulo (2013). Os trabalhos realizados permitiram a identificação de 1.398 processos erosivos lineares em áreas urbanas e 39.864 processos erosivos lineares em áreas rurais, gerando informações que permitiram caracterizar ravinas e boçorocas de diferentes tipos quanto à origem e forma de ocorrência, bem como relacionar os principais condicionantes do meio físico e as áreas de concentração desse tipo de processo em todo o Estado. Para a área de trabalho selecionada, foram detectados 508 processos, sendo 204 ravinas e 304 boçorocas. O método de registro dos processos, em resumo, baseou-se em: a. identificação dos processos erosivos a partir das imagens orbitais; b. elaboração de fichas de cadastro; c. visitas de campo; d. compilação dos dados obtidos e comparação dos resultados. 
Todos os registros foram coletados no sistema de projeção geográfica associados ao sistema geodésico WGS - 1984. A espacialização dos pontos utilizados foi feita através do software pela geração de um arquivo shapefille no formato de pontos.

Para análise espacial dos registros utilizou-se o estimador probabilístico nãoparamétrico de densidade de Kernel ("Kernel Estimation"), uma ferramenta básica e amplamente utilizada para caracterização da distribuição espacial de pontos. A técnica de estimação por Kernel consiste em estudar o comportamento dos padrões pontuais, estimando a densidade pontual do processo em toda região de estudo por meio de um ajuste de uma função bidimensional dos eventos considerados, compondo em uma superfície da qual o valor será proporcional das amostras por unidade de área. Essa técnica (também conhecido como estimador de intensidade) realiza uma contagem de todos os pontos dentro de uma região de influência ponderando-os pela distância de cada um à localização de interesse (Câmara et. al., 2004). O produto gerado é uma grade em que cada célula representa o valor de densidade, intensidade ou razão entre atributos. $\mathrm{O}$ valor estimado em cada célula é uma probabilidade de encontrar um evento (caso), ponderada pela distância para os eventos observados.

Para o presente trabalho, adotou-se a aplicação da função de Kernel quártico e largura de banda de aproximadamente 50 metros, definida pelo módulo Analysis Tools - Proximity - Buffer (ARCGIS 10.2.1).Essa versão do software dispõe de um algoritmo de raio de busca padrão (bandwidth)que se baseia na entrada de dados de pontos da amostra e é definido pela fórmula apresentada na equação 1 .

$$
\text { Raio de Busca }=0,9 * \min \left(R B, \sqrt{\frac{1}{1 n(2)}} * D m\right) * n^{-0.2}
$$

em que:

$R B$ é a distância padrão entre os pontos da amostra;

$D m$ é a distância média entre os pontos da amostra e;

$n$ é o número de pontos da amostra.

A aplicação dessa ferramenta foi empregada para análise de ocorrência na distribuição dos registros a fim de identificar áreas com maiores concentrações de densidades de processos erosivos de diferentes tipos. Para os mapeamentos gerados, considerou-se a classificação de zonas de alta, média e baixa densidade de processos erosivos baseada nos valores estimados de Kernel divididos em intervalos iguais ("equal intervals").

\subsection{Etapa 3: Geração de Dados Topográficos - Hipsometria e Declividade}

Para geração de dados de características topográficas da área de análise utilizou-se a base de dados gratuita fornecida pela Secretaria do Meio Ambiente do Estado de São Paulo e pelo Instituto de Pesquisas Espaciais - IPT. Foram utilizadas informações referentes à rede de drenagem, pontos cotados de altimetria e curvas de 
nível oriundos de cartas de mapeamentos sistemáticos do Instituto Brasileiro de Geografia e Estatística (IBGE), Instituto Geográfico Geológico (IGG) e Departamento de Serviços Geográficos do Exército, na escala 1:50.000 (projeto GISAT), no formato shapefille.

Para a extração dos dadosde hipsometria e declividade, gerou-se, a partir das curvas de níveis, pontos cotados e rede de drenagem, um MDT (Modelo Digital de Terreno), com resolução de $50 \mathrm{~m}^{2}$ (grid de $25 \times 25 \mathrm{~m}$ ) no programa ARCGIS 10.2.1 (módulo 3D Analyst-Raster Interpolation - Topo to Raster). Segundo Rabaco (2005), esse módulo possui como principais vantagens a coerência nas análises hidrológicas e a continuidade da superfície, ausente nos demais métodos (ex. krigagem), resultando em uma estrutura de drenagem conectada e produzindo alta acurácia na superfície. Ainda segundo Guimarães (2000), este módulo utiliza também uma técnica de interpolação de interação de diferenças finitas, combinando a eficiência de uma interpolação local com métodos de interpolação global, os quais utilizam uma superfície de continuidade, como o interpolador Kriging. Além disso, segundo o mesmo autor, esse tipo de interpolação gera uma estrutura de drenagem hipotética, eliminando depressões que não estão de acordo com o fluxo gravitacional. Os intervalos definidos para apresentação do mapa de hipsometria foram baseados na observação da distribuição de valores de altimetria existentes na área de estudo.

Para o mapeamento de declividade, aplicou-se ao MDT gerado a ferramenta Slope (módulo 3D Analyst - Surface - Slope). As classes de declividade para apresentação do resultado final foram definidas baseadas nos trabalhos já publicados de Stábile $(2009,2013)$ e em metodologias com definições de intervalos já consagrados nos estudos de capacidade de uso/aptidão agrícola, associados com aqueles conhecidos como valores limites críticos da geotecnia, indicativos respectivamente do vigor dos processos erosivos, dos riscos de escorregamentos/deslizamentos e inundações frequentes (SALOMÃO, 1994; ROSS, 1994 e 1995; CREPANI, 2001).

\subsection{Etapa 4: Análise Conjunta - Relação entre Características Topográficas e Tipos de Processos Erosivos}

Para a investigação da relação entre os tipos de processos erosivos associados às variáveis hipsométricas e de declividade foi realizada uma análise conjunta subsidiada por medidas estatísticas (teste qui-quadrado) e técnicas de geoprocessamento baseadas em análises espaciais básicas (overlay e interseção).

$\mathrm{O}$ teste qui-quadrado, simbolizado por $X^{2}$, é um teste de hipóteses nãoparamétrico que se destina a encontrar um valor de dispersão para duas variáveis nominais e avaliar a associação existente entre variáveis qualitativas. Para esse caso, foram estipuladas hipóteses para testar a associação entre tipos de processos erosivos e características topográficas. A amostra continha todos os pontos de erosão mapeados na área de análise associados a valores de intervalos de declividade e hipsometria mapeados. Para a realização das análises, foi utilizado o programa 
estatístico SPSS 22 (Statistical Package for the Social Sciences.As hipóteses analisadas foram:

Hipótese nula: variáveis não apresentam dependência; no caso específico, tipo de processo erosivo não está associado ao grau de declividade ou valor de hipsometria.

Hipótese alternativa: variáveis apresentam dependência; no caso específico, tipo de processo erosivo está associado ao grau de declividade ou valor de hipsometria.

Já as técnicas de análise espacial aplicadas utilizaram os mapeamentos resultantes das etapas 2 e 3, respectivamente: mapa de valores de intensidade de processos erosivos classificados por tipo de processo e mapeamentos de intervalos hipsométricos e de declividade referentes à área de análise. Para análise da distribuição dos tipos de processos erosivos ao longo das classes de declividade e hipsometria contidos no trecho de análise foi feita uma sobreposição das informações das áreas das zonas de intensidade dos processos (alta, média e baixa) com os mapeamentos topográficos gerados. Os arquivos no formato raster foram manuseados no módulo 3D Analystatravés da ferramenta Raster Calculator(ARCGIS 10.2.1), que realiza a operação de overlay entre as informações selecionadas.

\section{RESULTADOS}

\subsection{Processos Erosivos}

No total, foram mapeados 304 registros de processos erosivos ao longo do trecho em análise. A figura 4 ilustra os são exemplos dos registros mapeados em campo. Já as Figuras 5, 6 e 7são, respectivamente, os resultados dos mapeamentos de densidade de ocorrência (baixa, média e alta) gerados a partir do comportamento da distribuição espacial dos registros totais e classificados por tipo de gravidade (ravinas e voçorocas).

Os processos classificados como boçorocas representam cerca de $60 \%$ do total de registros mapeados, enquanto que as ravinas aparecem mapeadas em menor quantidade. Ambos os tipos de feições concentram-se, em sua maioria, nas áreas de aterro das plataformas das linhas. São estágios mais avançados do processo erosivo e podem, muitas vezes, serem considerados irreversíveis.

Conforme definido na metodologia (ítem 4.2), o mapeamento de densidade de processos identificou áreas com concentrações de registros, considerando a distribuição total dos pontos mapeados e a distribuição dos registros considerando as classificações quanto ao tipo de processo. Para todos os mapeamentos gerados, admitiu-se as classificações de alta, média e baixa densidade baseado nos valores de estimadores de Kernel divididos em intervalos iguais ("equal intervals"). Na Figura 5, é possível notar que a área mais afetada pela incidência de processos erosivos, considerando a totalidade dos registros, é o trecho da linha que percorre por entre o limite do município de Conchas, em um trajeto de aproximadamente $8 \mathrm{~km}$. A área mapeada como alta densidade de processos erosivos concentra cerca de $25 \%$ do 
total das feições mapeadas. Os municípios de Jurumim e a divisa das cidades de Boituva e Cerquilho também apresentam áreas de média densidade de ocorrência, justificada pela concentração de boçorocas nessas regiões (Figura 7).

Figura 4 - Exemplos dos registros mapeados em campo: à esquerda: boçorocas; à direita: ravinas.

Fonte: Instituto de Pesquisas Tecnológicas (IPT)
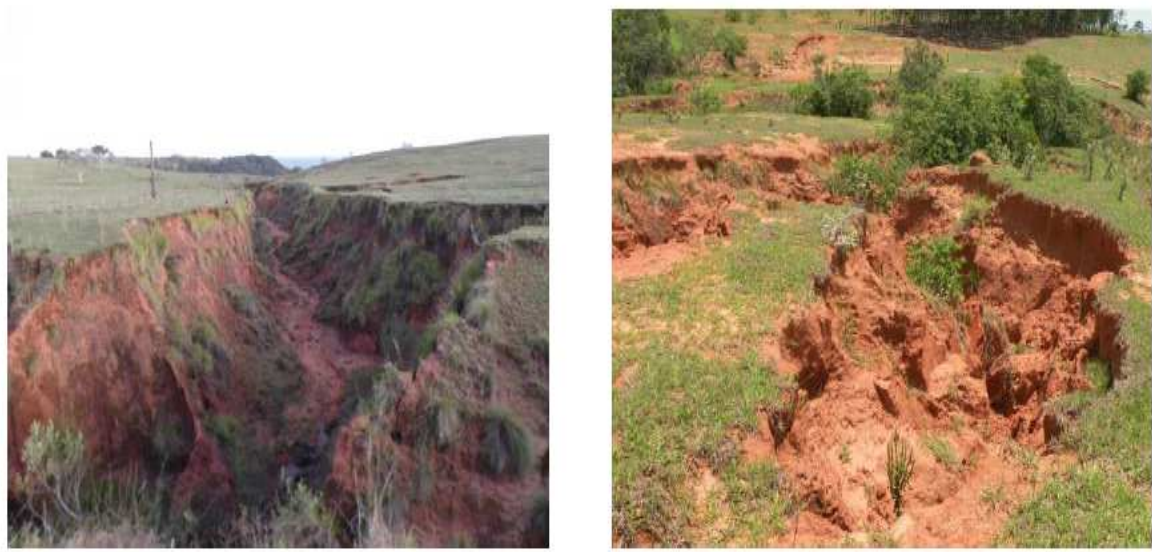

Figura 5 - Densidade de ocorrência: total dos registros.

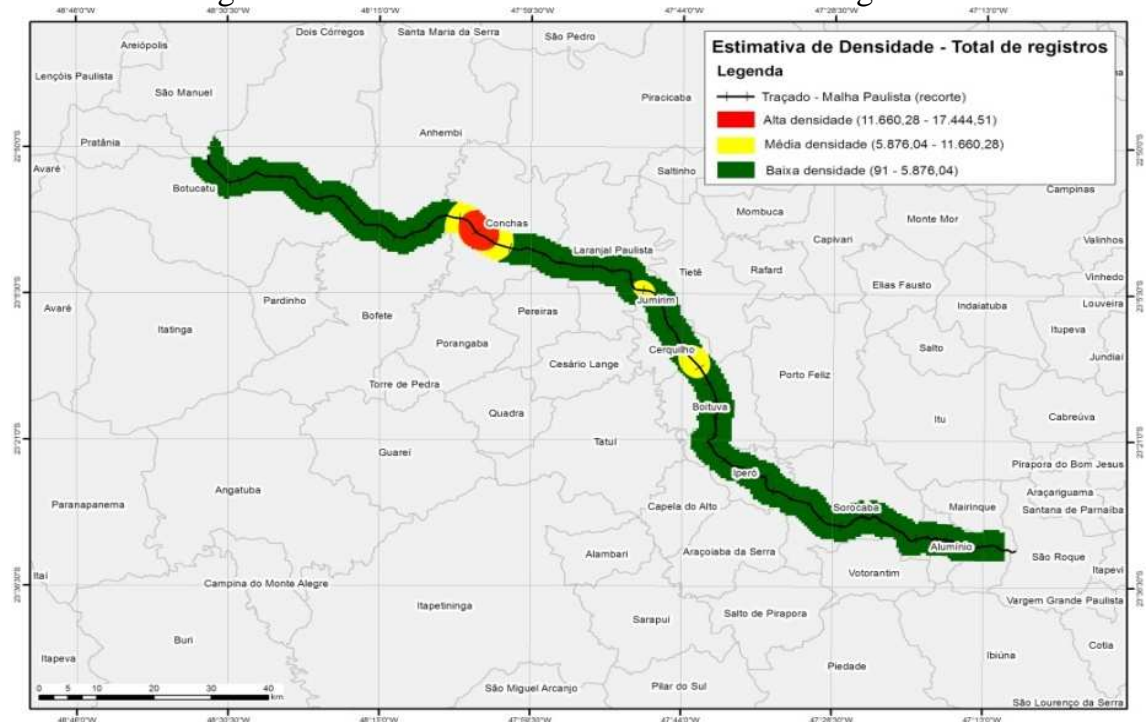

Bol. Ciênc. Geod., sec. Artigos, Curitiba, v. 20, no 4, p.947-969, out-dez, 2014. 


$$
2
$$


Figura 7 - Densidade de ocorrência: boçorocas.

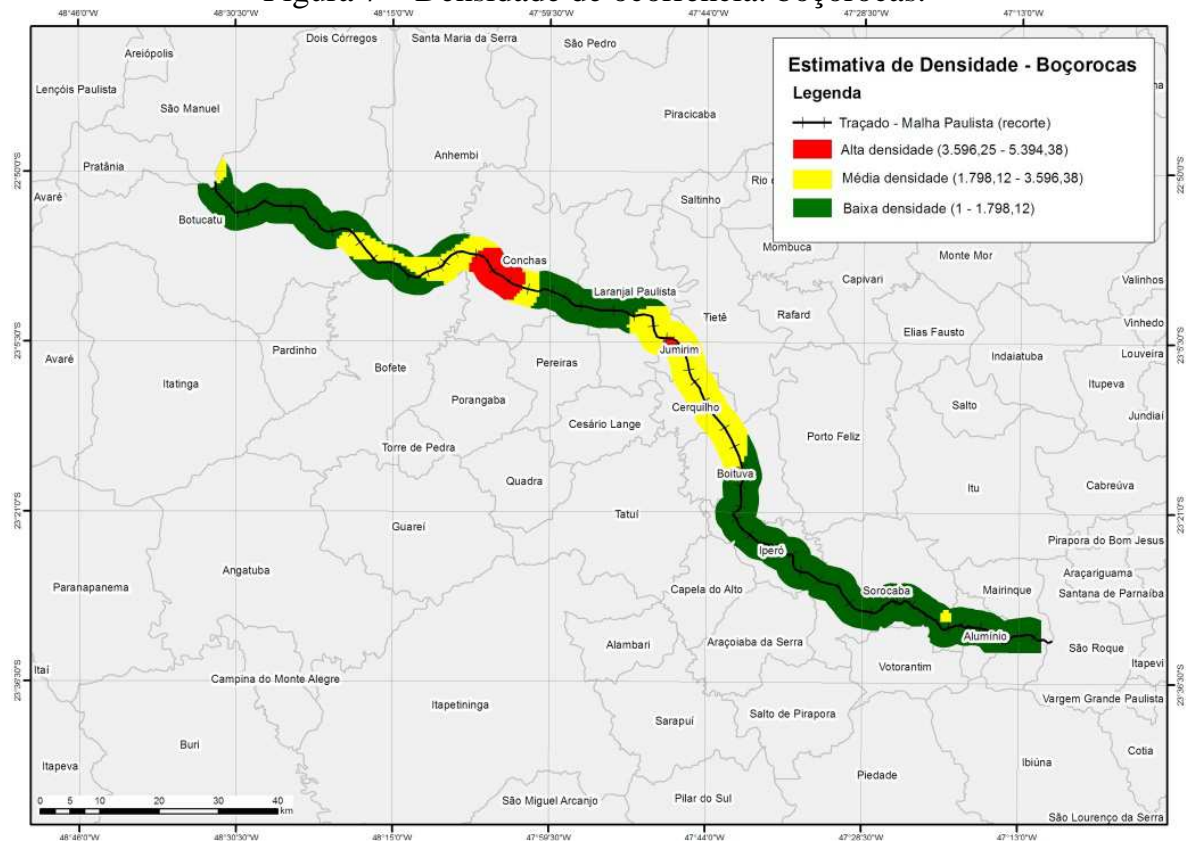

\subsection{Dados Topográficos}

A sobreposição das informações topográficas possibilitou extrair o percentual de cada intervalo de declividade e hipsometria encontrado ao longo do trajeto da linha e da área considerada para análise (buffer). As Figuras 8 e 9 apresentam os mapeamentos das variáveis topográficas. Já as Tabelas 1 e 2 resumem os resultados encontrados.

Através do mapa e dados expostos, é possível observar que a Malha Paulista apresenta maiores percentuais de áreas com valores de declividade no intervalo de até $3^{\circ}$ e acima de $8^{\circ}$ até $15^{\circ}$, com concentrações situadas entre o trecho de Laranjal Paulista - Conchas e Iperó - Boituva. De modo geral, declividades de até $6^{\circ}$ são classificadas como intervalos de terrenos propensos a níveis com fragilidade ambiental muito baixa (ROSS, 1995).

As demais classes mapeadas apresentam distribuições similares quanto o percentual de área contida em cada intervalo. Os trechos com maiores declividades estão concentrados nos extremos da linha férrea, nos municípios de Botucatu, Mairinque e Alumínio. De acordo com Ross (2000), classes de declividade acima $15^{\circ}$ estão propensas às classificações de alta a muito alta fragilidade ambiental e suscetibilidade à erosão. 
Tabela 1 - Declividade - Área $\left(\mathrm{km}^{2}\right)$ e Percentual (\%) por Intervalo.

\begin{tabular}{c|c|c}
\hline Declividade & \multicolumn{2}{|c}{ Área de análise (buffer $\mathbf{3} \mathbf{k m})$} \\
\hline Intervalos & Área $\left(\mathbf{k m}^{\mathbf{2}}\right)$ & Percentual $(\%)$ \\
\hline até $\mathbf{3}$ & 419,31 & 36,33 \\
\hline $\mathbf{>} \mathbf{3} \mathbf{5}$ & 183,99 & 15,94 \\
\hline $\mathbf{5} \mathbf{- 8}$ & 205,218 & 17,78 \\
\hline$>\mathbf{8}-\mathbf{1 5}$ & 219,92 & 19,05 \\
\hline$>\mathbf{1 5}$ & 125,86 & 10,90 \\
\hline Total & $\mathbf{1 . 1 5 4 , 3 0}$ & $\mathbf{1 0 0}$ \\
\hline
\end{tabular}

Figura 8 - Características topográficas: Declividade.

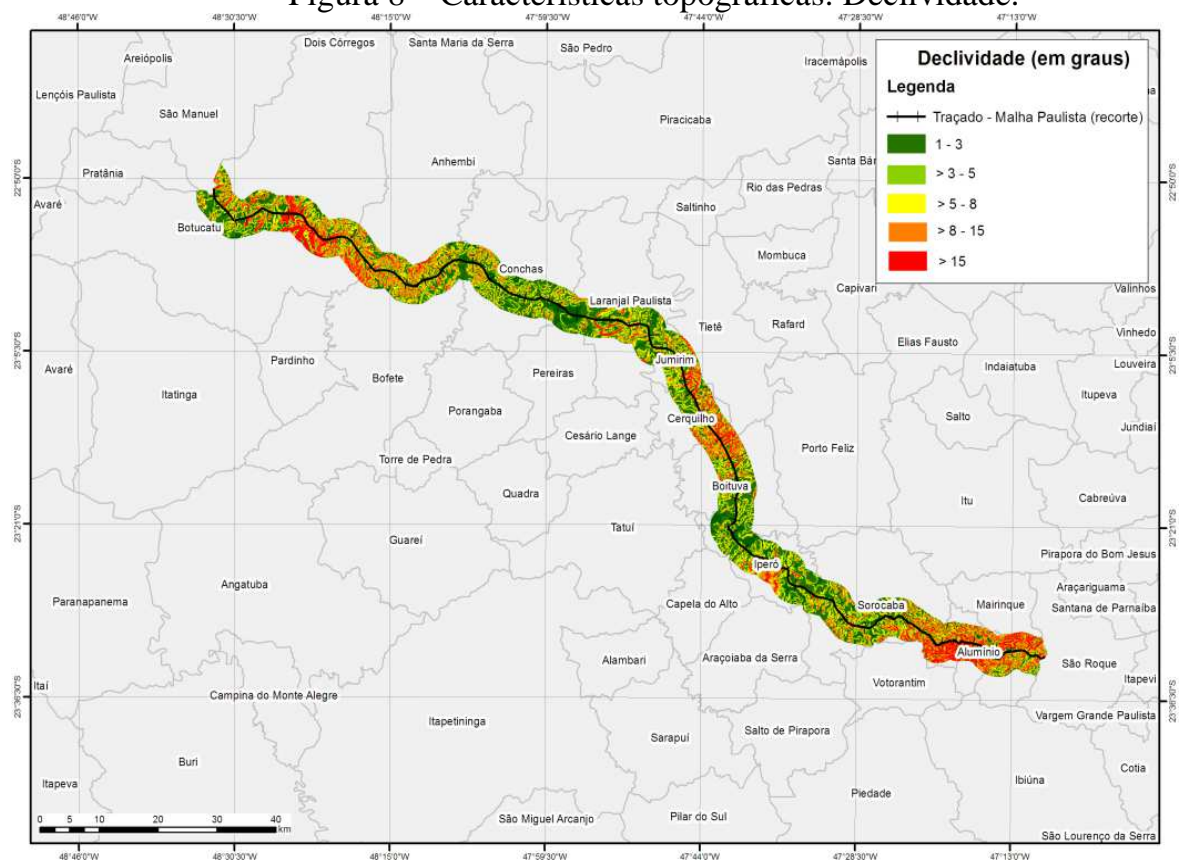

Em relação aos dados de hipsometria, o trecho da Malha Paulista concentra aproximadamente $70 \%$ da área de análise considerada no intervalo de até $700 \mathrm{~m}$. Assim como nos trechos com registros de maiores declividades, os registros de maiores altitudes (acima de $900 \mathrm{~m}$ ) estão localizados nos extremos da região de análise. Em relação aos intervalos menores, o trecho não apresenta altitudes inferiores a $300 \mathrm{~m}$, classes correspondentes aos fundos de vales principais e ao terço inferior das vertentes. Isso se deve ao fato de, no estado de SP, os desenhos dos 
traçados das principais linhas férreas localizam-se nas cabeceiras de drenagem, atuando como divisores de água, coincidindo com os limites topográficos das bacias hidrográficas do estado.

Tabela 2 - Hipsometria - Área $\left(\mathrm{km}^{2}\right)$ e Percentual (\%) por Intervalo

\begin{tabular}{c|c|c}
\hline Hipsometria & \multicolumn{2}{|c}{ Área de análise (buffer $-\mathbf{3 k m})$} \\
\hline Intervalos & Área $\left(\mathbf{k m}^{\mathbf{2}}\right)$ & Percentual $\mathbf{( \% )}$ \\
\hline $\mathbf{3 0 0 - 5 0 0}$ & 126,23 & 10,94 \\
\hline $\mathbf{5 0 0 - 7 0 0}$ & 787,37 & 68,21 \\
\hline $\mathbf{7 0 0 - 9 0 0}$ & 219,6 & 19,02 \\
\hline$>\mathbf{9 0 0}$ & 21,098 & 1,83 \\
\hline Total & $\mathbf{1 . 1 5 4 , 3 0}$ & $\mathbf{1 0 0}$ \\
\hline
\end{tabular}

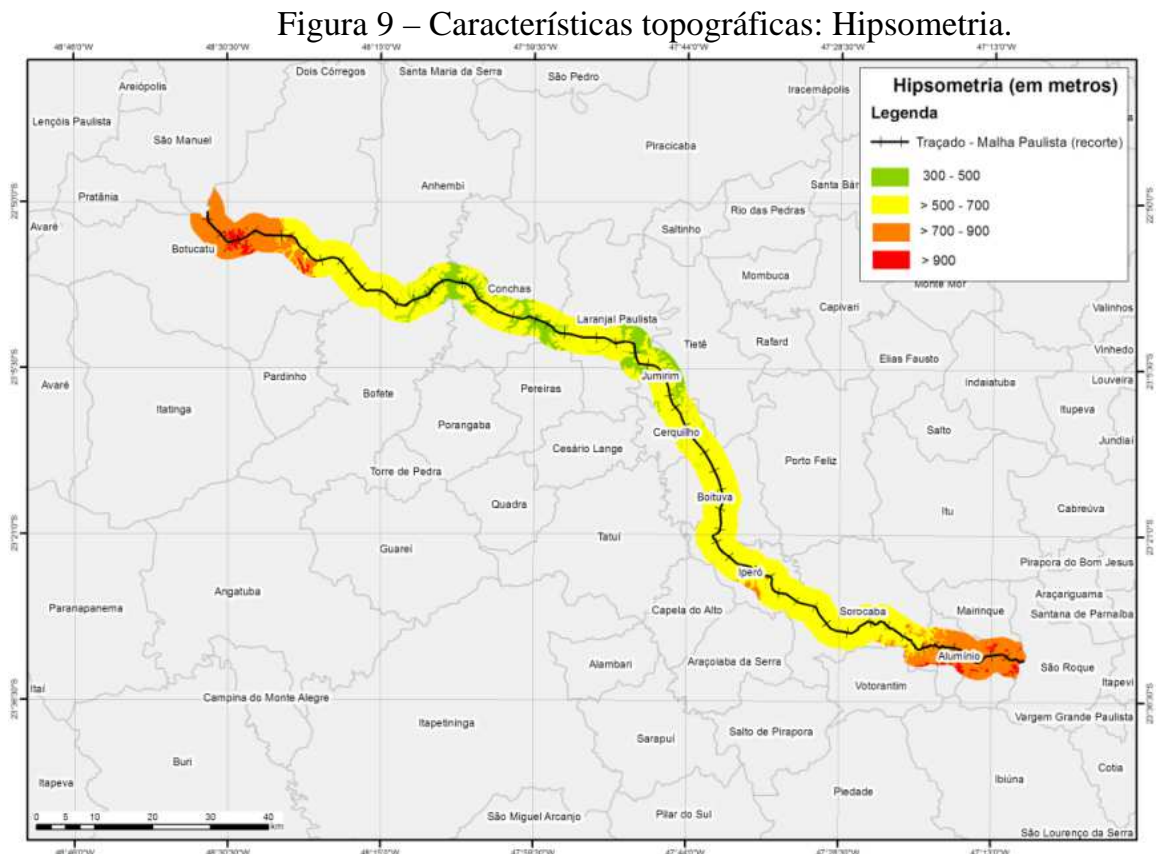

\subsection{Análise Conjunta}

Os resultados da aplicação do teste qui-quadrado ( seguem resumidos nas Tabelas 3 e 4 . As Figuras 10 e 11 são histogramas complementares para a interpretação e melhor visualização dos resultados.

Para ambas as análises, a um nível de significância de $0,05 \%$, os testes sugerem a rejeição da hipótese nula, permitindo afirmar que a hipótese apontada, a partir dos resultados obtidos, é de que as variáveis apresentam dependência; no caso 
específico, tipo de processo erosivo está associado às classes de declividade e de hipsometria das vertentes em que ocorrem.

$\mathrm{Na}$ aplicação do teste qui-quadrado para o caso da variável declividade, observar-se que a associação se deve, principalmente, às concentrações dos processos de ravinas nos intervalos de $5-8^{\circ}$ e o de boçorocas em intervalos maiores, de $8^{\circ}-15^{\circ}$. Além disso, os resultados apontam que, no universo de registros considerados, apesar da maioria dos processos de boçorocas estarem localizados em declividades superiores a $8^{\circ}$, outra quantidade expressiva desses encontra-se em vertentes de até $3^{\circ}$ (diferente dos processos de ravina). Em outras palavras, erosões do tipo boçoroca, embora mais agressivas que as ravinas, do ponto de vista de recuperação do solo e irreversibilidade do processo, desenvolvem-se, na área analisada, tanto em áreas mais declivosas quanto em áreas de declividade baixa (Tabela 3 e Figura 10).

Já para o caso da variável hipsométrica, a distribuição dos percentuais de processos de ambos os tipos parecem apresentar maior homogeneidade: tanto para os casos de ravinas quanto para os casos de boçorocas, a concentração se deve aos intervalos de altitudes intermediárias $(500-70)$, talvez por este representar a classe de maior área proporcional no trecho analisado $(68,21 \%$ da área total analisada concentram-se em altitudes acima de $500 \mathrm{~m}$ até $700 \mathrm{~m})$. Porém, a proporção de processos do tipo boçorocas localizados em altitudes acima de $700 \mathrm{~m}$ (em comparação aos processos de ravina) indica a possível associação constatada pelo teste aplicado.

Tabela 3 - Teste qui-quadrado $\left(X^{2}\right)$ para tipos de processos erosivos (boçoroca, ravina) e intervalos de declividade.

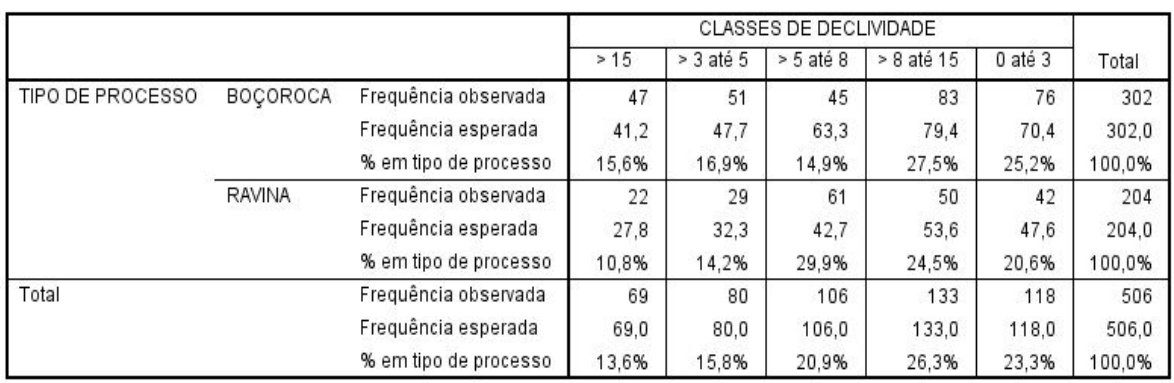

Testes qui-quadrado

\begin{tabular}{|l|r|r|r|}
\hline & \multicolumn{1}{|c|}{ Valor } & df & $\begin{array}{r}\text { Significância } \\
\text { Sig. (2 lados) }\end{array}$ \\
\hline $\begin{array}{l}\text { Qui-quadrado de } \\
\begin{array}{l}\text { Pearson } \\
\text { Razão de } \\
\text { verossimilhança } \\
\text { N de Casos Válidos }\end{array}\end{array}$ & $17,172^{\text {a }}$ & 4 &, 002 \\
\hline
\end{tabular}

Bol. Ciênc. Geod., sec. Artigos, Curitiba, v. 20, nº 4, p.947-969, out-dez, 2014. 
Figura 9 - Histograma: declividade x processos erosivos.

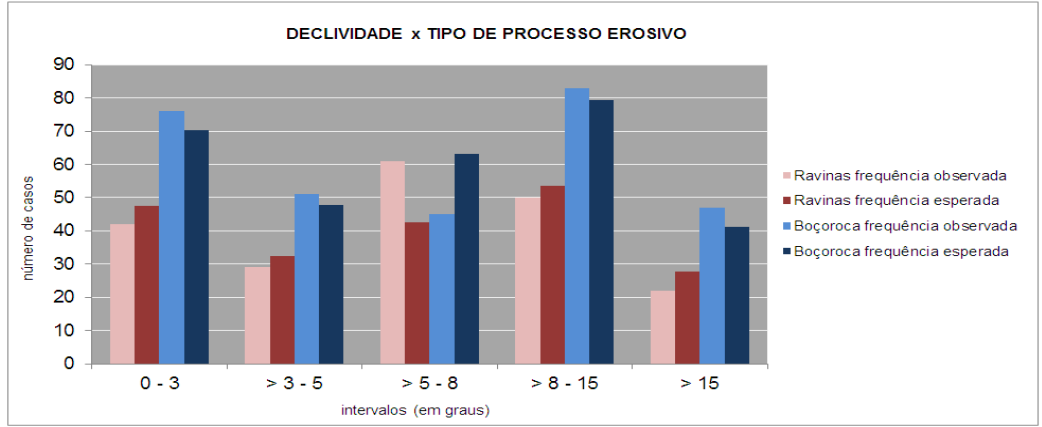

Tabela 4. Teste qui-quadrado ( para tipos de processos erosivos (boçoroca, ravina) e intervalos de hipsometria.

\begin{tabular}{|c|c|c|c|c|c|c|c|}
\hline & & & \multicolumn{4}{|c|}{ CLASSES DE HIPSOMETRIA } & \multirow[b]{2}{*}{ Total } \\
\hline & & & $>300$ até 500 & $>500$ até 700 & $>700$ até 900 & $>900$ & \\
\hline \multirow[t]{6}{*}{ TIPO DE PROCESSO } & BOÇOROCA & Frequência observada & 7 & 238 & 54 & 3 & 302 \\
\hline & & Frequência esperada & 5,4 & 251,9 & 42,4 & 2,4 & 302,0 \\
\hline & & $\%$ em tipo de processo & $2,3 \%$ & $78,8 \%$ & $17,9 \%$ & $1,0 \%$ & $100,0 \%$ \\
\hline & RAVINA & Frequência observada & 2 & 184 & 17 & 1 & 204 \\
\hline & & Frequência esperada & 3,6 & 170,1 & 28,6 & 1,6 & 204,0 \\
\hline & & $\%$ em tipo de processo & $1,0 \%$ & $90,2 \%$ & $8,3 \%$ & $0,5 \%$ & $100,0 \%$ \\
\hline \multirow[t]{3}{*}{ Total } & & Frequência observada & 9 & 422 & 71 & 4 & 506 \\
\hline & & Frequência esperada & 9,0 & 422,0 & 71,0 & 4,0 & 506,0 \\
\hline & & $\%$ em tipo de processo & $1,8 \%$ & $83,4 \%$ & $14,0 \%$ & $0,8 \%$ & $100,0 \%$ \\
\hline
\end{tabular}

\begin{tabular}{|c|c|c|c|}
\hline & Valor & df & $\begin{array}{l}\text { Significância } \\
\text { Sig. (2 lados) }\end{array}$ \\
\hline $\begin{array}{l}\text { Qui-quadrado de } \\
\text { Pearson }\end{array}$ & $11,417^{\mathrm{a}}$ & 3 & .010 \\
\hline $\begin{array}{l}\text { Razão de } \\
\text { verossimilhança }\end{array}$ & 12,083 & 3 & .007 \\
\hline $\mathrm{N}$ de Casos Válidos & 506 & & \\
\hline
\end{tabular}

Figura 10 - Histograma: hipsometria x processos erosivos.

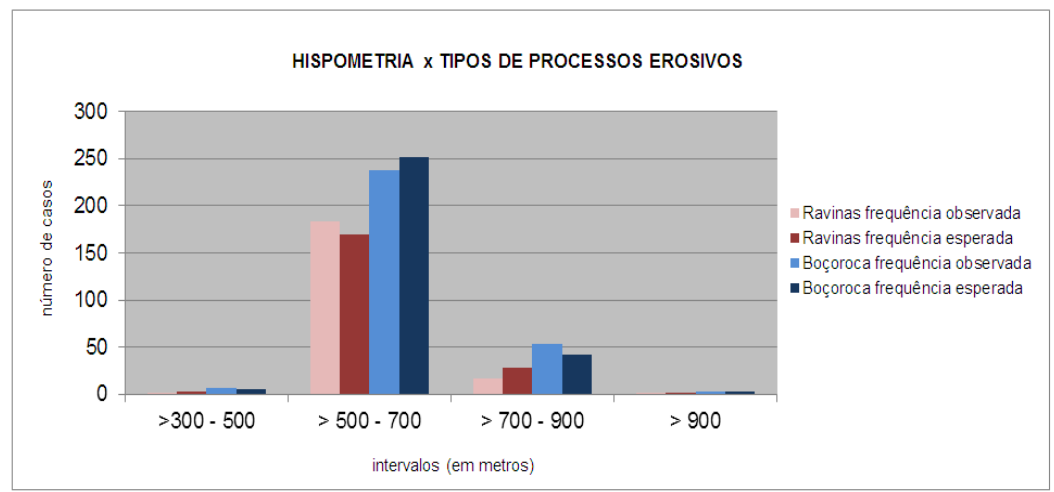

Bol. Ciênc. Geod., sec. Artigos, Curitiba, v. 20, nº 4, p.947-969, out-dez, 2014. 
Em sequência, a Tabela 5 apresenta os resultados da aplicação das técnicas de geoprocessamento (descritas no ítem 4.4). Nela é resumida a distribuição das áreas de alta, média e baixa densidade dos processos classificados como ravina e boçorocas nos intervalos de declividade e hipsometria mapeados.

Tabela 5 - Cruzamentos das variáveis espaciais (densidade de processos - por tipo e dados de topografia- declividade e hipsometria) em SIG.

\begin{tabular}{l|r|r|r}
\hline TIPO DE PROCESSO: RAVINAS \\
\hline Hipsometria & Alta densidade (\%) & Média densidade (\%) & Baixa densidade (\%) \\
\hline até 300 & 0,000 & 0,000 & 0,021 \\
\hline$>300 \cdot 500$ & 25,492 & 15,884 & 9,064 \\
\hline$>500 \cdot 700$ & 74,508 & 84,116 & 73,189 \\
\hline$>700 \cdot 900$ & 0,000 & 0,000 & 17,549 \\
\hline$>900$ & 0,000 & 0,000 & 0,177 \\
\hline Total & 100 & 100 & 100 \\
\hline
\end{tabular}

\begin{tabular}{l|r|r|r}
\hline TIPO DE PROCESSO: BOÇOROCAS \\
\hline Hipsometria & Alta densidade $(\%)$ & Média densidade $(\%)$ & Baixa densidade (\%) \\
\hline até 300 & 0,000 & 0,000 & 0,018 \\
\hline$>300 \cdot 500$ & 23,354 & 16,517 & 7,884 \\
\hline$>500 \cdot 700$ & 76,646 & 71,569 & 66,988 \\
\hline$>700 \cdot 900$ & 0,000 & 11,914 & 23,656 \\
\hline$>900$ & 0,000 & 0,000 & 1,455 \\
\hline Total & 100 & 100 & 100 \\
\hline
\end{tabular}

\begin{tabular}{|c|c|c|c|}
\hline \multicolumn{4}{|c|}{ TIPO DE PROCESSO: RAVINAS } \\
\hline Declividade & Alta densidade (\%) & Média densidade (\%) & Baixa densidade (\%) \\
\hline $0-3$ & 22,228 & 24,389 & 33,650 \\
\hline$>3 \cdot 5$ & 14,488 & 16,012 & 18,380 \\
\hline$>5-8$ & 28,130 & 22,251 & 18,910 \\
\hline$>8-15$ & 29,717 & 33,028 & 19,630 \\
\hline$>15$ & 5,437 & 4,319 & 9,420 \\
\hline Total & 100 & 100 & 100 \\
\hline \multicolumn{4}{|c|}{ TIPO DE PROCESSO: BOÇOROCAS } \\
\hline Declividade & Alta densidade $(\%)$ & Média densidade (\%) & Baixa densidade (\%) \\
\hline $0-3$ & 33,192 & 22,116 & 24,962 \\
\hline$>3-5$ & 21,131 & 16,995 & 17,651 \\
\hline$>5-8$ & 26,542 & 21,364 & 20,686 \\
\hline$>8-15$ & 18,047 & 26,201 & 22,964 \\
\hline$>15$ & 1,088 & 13,325 & 13,737 \\
\hline Total & 100 & 100 & 100 \\
\hline
\end{tabular}

Bol. Ciênc. Geod., sec. Artigos, Curitiba, v. 20, nº 4, p.947-969, out-dez, 2014. 
O mapeamento das áreas densidade, além de considerar os processos observados em campo (existentes), fornece uma informação de probabilidade de ocorrência de zonas de concentração de ocorrência associadas à localização de processos no entorno (raio) do ponto analisado (conforme descrito no ítem 4.4). Apesar da técnica aplicada não ter como resultado final um valor estatístico que analise a associação (ou independência) das variáveis em questão, podemos identificar, a partir dos dados espaciais gerados para ambos os tipos de processos:

- a concentração, tanto de ravinas quanto de boçorocas, nos intervalos de declividades até $15^{\circ}$; para declividades acima, a concentração de processos diminui consideravelmente em ambos os casos;

- distribuições dos percentuais de áreas de alta, média e baixa densidade de de ravinas e boçorocas apresentam distribuições parecidas por entre os intervalos de declividade e hipsometria considerados;

- nos intervalos de altitudes $>300 \mathrm{~m}-500 \mathrm{~m}$ e $>700-900 \mathrm{~m}$ estão concentradas as áreas totaisdas zonas de alta densidade de ocorrência de ravinas e boçorocas;

- nos intervalos de altitudes $>500 \mathrm{~m}$ até $700 \mathrm{~m}$ desenvolvem-se grandes proporções de zonas de alta, média e baixa densidade de ocorrência tanto de ravinas quanto de boçorocas.

\section{CONSIDERAÇÕES FINAIS}

As aplicações dos procedimentos metodológicos expostos no ítem 4.4 tiveram como objetivo investigar se existe associação, como definido nos objetivos da presente pesquisa, entre o desenvolvimento dos tipos de processos erosivos lineares mapeados e características topográficas (declividade e hipsometria). Os métodos aplicados, caso comprovassem associação entre as variáveis analisadas, poderiam subsidiar ações de mitigação e prevenção de processos erosivos ao longo do trecho da linha férrea analisada, contribuindo na implementação e planejamento para o cumprimento de políticas e requisitos ambientais impostos à condição de operação e funcionamento da malha, além de indicar ações voltadas ao monitoramento de intervalos específicos de hipsometria e declividade, associados ao desenvolvimento de diferentes tipos de processos erosivo.

A comparação dos resultados permitiu avaliar a importância da variável espacial na problemática tratada. A análise dos testes estatísticos não-paramétricos apontou que existe associação estatisticamente significativa entre as variáveis estudadas. Já as técnicas de geoprocessamento e o uso de informações espaciais, apesar de não fornecerem um valor estatístico que permita inferir a associação entre as variáveis analisadas, possibilitaram a observação da distribuição espacial dos fenômenos de erosão ao longo do trecho da ferrovia, indicando que tal comportamento não aponta, claramente, associação expressiva entre os tipos de processos e as características topográficas consideradas. 
Apesar de a presente pesquisa considerar apenas aspectos topográficos no estudo das erosões analisadas, a ocorrência e desenvolvimento de processos erosivos, não só nas áreas de entorno de empreendimentos lineares (como ferrovias), são ocasionados por fatores diversos, tais como características ambientais, ocupação e manejo do solo e aceleração do processo natural por ação antrópica. Dessa forma, os resultados aqui apontados podem colaborar em estudos futuros, complementando a análise de agentes associados ao desencadeamento de erosões em seus diferentes tipos de classificação.

\section{AGRADECIMENTOS}

Os autores desejam expressar seus agradecimentos à CAPES e ITL pela bolsa de estudos concedida; à ALL(América Latina Logística) pelo apoio a pesquisa desenvolvida e ao DAEE (Departamento de Águas e Esgoto) pela autorização de utilização de dados; ao CNPq pela bolsa de produtividade, ao Instituto de Pesquisas Tecnológicas - IPT e a Fundação de Apoio ao Instituto de Pesquisas Tecnológicas FIPT pela concessão da bolsa de pós-graduação do projeto Novos Talentos.

\section{REFERÊNCIAS BIBLIOGRÁFICAS}

ALMEIDA FILHO, G. S. Diagnóstico de Processos Erosivos Lineares associados a Eventos Pluviosos no município de Bauru, SP. Dissertação de Mestrado, UNICAMP, 2000. 224p.

ANTONANGELO, A.; FENNER, P. T. Identificação de riscos de erosão em estradas de uso florestal através do critério do fator topográfico LS. Energia Agrícola, Botucatu, v.20, n.3, p.1-20, 2005.

BERTONI, J.; LOMBARDI NETO, F. Conservação do solo.Ícone,São Paulo, 1990.

BIGARELlA, J.J. e MAZUCHOWSKI, J. Visão Integrada da Problemática da Erosão. Associação Brasileira de Geologia de Engenharia - ABGE, São Paulo, 1985.

COELHO NETTO, A. L. Hidrologia de Encosta na Interface com a Geomorfologia. In: Geomorfologia: uma atualização de bases e conceitos. Bertrand Brasil, Rio de Janeiro, 1994.

CÂMARA, G.; DAVIS, C.; MONTEIRO, A. M. V. \& D'ALGE, J. C. Introdução à Ciência da Geoinformação. Instituto Nacional de Pesquisas Espaciais - INPE, São José dos Campos, 2004.

CREPANI, E.; MEDEIROS, J. S.; AZEVEDO, L. G.; DUARTE, V.; HERNANDEZ, P.; FLORENZANO, T; BARBOSA, C. Sensoriamento Remoto e Geoprocessamento Aplicados ao Zoneamento Ecológico-Econômico e ao Ordenamento Territorial. Instituto Nacional de Pesquisas Espaciais INPE, São José dos Campos, 2001.

DAEE - DEPARTAMENTO DE ÁGUAS E ENERGIA. Controle de Erosão. Departamento de Águas e Energia, São Paulo, 1990. 
DE ROO, A. P. J. Modelling runoff and sediment transport in catchments using GIS. Hydrol Process, v.12, p. 905 - 922, 1998.

DRUCK, S.; CARVALHO, M. S.; CÂMARA, G.; MONTEIRO, A. V. M. Análise Espacial de Dados Geográficos. EMBRAPA, Brasília, 2004

GUERRA, A. J. T.; CUNHA, S. B. Geomorfologia: uma atualização de bases e conceitos. $2^{\circ}$ ed. Bertrand Brasil, Rio de Janeiro, 1994.

GUERRA, A. J. T.; CUNHA, S. B. Degradação ambiental. In: Geomorfologia e Meio Ambiente. Bertrand Brasil, Rio de Janeiro, 1995.

GUIMARÃES, R. F. Utilização de um Modelo de Previsão de Áreas Susceptíveis a Escorregamentos Rasos com Controle Topográfico: Adequação e Calibração em Duas Bacias de Drenagem. Tese de Doutorado. UFRJ, 2000. 327p.

LEVINE, D.M; STEPHAN, D. F; KREHBIEL, T. C.; BERENSON, M. L. Estatística: Teoria e Aplicações Usando o Microsoft Excel em Português. $6^{\circ}$ ed. LTC, Rio de Janeiro, 2000.

LEPSCH, I. F. Formação e Conservação dos Solos. Oficina de Textos, São Paulo, 2000.

MANFRÉ, L. A.; SILVA, A.M.; URBAN, R.C; RODGERS, J. Environmental fragility evaluation and guidelines for environmental zoning: a study case on Ibiúna (the Southeastern Brazilian region). Environmental Earth Sciences, v. 69, p. 947 - 957, 2013.

MORGAN, R. P. C. Soil Erosion and Conservation. $3^{\circ}$ ed. Blackwell Plublishing, Oxford, 2005.

PINHEIRO, L. Z.; CUNHA, C. M. L. A importância da geração do fator topográfico (ls) da eups para modelagem erosiva de bacia hidrográfica. Revista Geográfica de América Central (número especial EGAL), p. 1-13, 2011.

RABACO, L. M. Avaliação de Modelos de Susceptibilidade a Movimentos Gravitacionais de Massa numa Faixa de Dutos. Dissertação de Mestrado, UFRJ, 2005. 214p.

ROSS, J. L. S. Análise Empírica da Fragilidade dos Ambientes Naturais e Antropizados. Revista do Departamento de Geografia, v. 8, FFLCH -USP, São Paulo, 1994.

ROSS, J. L. S. Análise e Síntese na Abordagem Geográfica da Pesquisa para o Planejamento Ambiental. Revista do Departamento de Geografia, v. 9, FFLCH-USP, São Paulo, 1995.

ROSS, J. L. S. Zoneamento Ecológico-Econômico. Workshop - Metodologia de Zoneamento Ecológico-Econômico para a Região Nordeste. Fortaleza, Ceará, 2000.

SAlOMÃO, F. X. T. Controle e Prevenção dos Processos Erosivos. In: Erosão e Conservação dos Solos: conceitos, temas e aplicações. Bertrand Brasil, Rio de Janeiro, 1999.

SIMONS, L. I. Engineering Analysis of Fluvial Systems. Fort Collins: Simons, Li \& Associates , 1982. 
SPÖRL, C. Modelo de Fragilidade Ambiental Utilizando Redes Neurais Artificiais. Tese de Doutorado. USP, 2007. 183p.

STABILE, R. A.;VIEIRA, B. C. Análise do papel exercido pela topografia na distribuição das feições erosivas da bacia hidrográfica Água da Faca, Piratininga (SP), a partir de um modelo digital de elevação. $12^{\circ}$ Congresso de Geógrafos da América Latina - EGAL. Montevideo, 2009.

VIDAL-TORRADO, P. V.; I. F. LEPESCH; CASTRO. S. S. Conceitos e Aplicações das Relações Pedologia- Geomorfologia em Regiões Tropicais Úmidas. In: Tópicos Especiais em Ciência do Solo. Sociedade Brasileira de Ciência do Solo, v. 4, p. 145-192, Viçosa, 2005.

SHIXIAN, G. The study on the relationship between land use and soil erosion in the Hengduan mountainous region of the Eastern Tibet. International Conference on Remote Sensing, Environment and Transportation Engineering, vol. 24-26, p. $902-905,2011$

SHUHUA, Z.; LIJUN, Z. Assessment of Soil Erosion in Suihua City Based on RUSLE and GIS. Computer Distributed Control and Intelligent Environmental Monitoring (CDCIEM), 2011.

ZHAO, X.L.; ZHANG, Z. X.; CY, L.W. Method of monitoring soil erosion dynamic based on remote sensing and GIS. Bulletin of Soil and Water Conservation, vol 22 (4), p. 29-32, 2002.

(Recebido em maio de 2014. Aceito em agosto de 2014). 